\title{
Developing a Workshop Using Double-Loop Learning to Enhance Student Teachers' Reflection
}

\author{
Sasaki Hironori \\ Chugokugakuen University
}

\begin{abstract}
The Faculty Student Teacher Professional Development course, which the author of this article teaches, decided to introduce a "reflective practitioner model" in 2014. Consequently, the faculty has developed several workshops of reflection to help student teachers to reflect their teaching practice as reflective practitioners so far. However, the student teachers' reflection tended to pertain to their underlying values and assumptions. Therefore, a development of workshop to facilitate the student teachers' reflection beyond their espoused theory and theory-in-use was required in this study. Argyris (1976) proposed "double loop learning theory" which was relevant to learning to change underlying values and assumptions. The focal point of the theory is how to solve problems that are complex and ill-structured like teaching practice. Double loop theory is based upon a "theory of action" perspective outlined by Argyris \& Schon (1974). The distinction between an individual's espoused theory and their "theory-in-use" (what they actually do) is an important aspect of the theory. It is necessary to interact with others in order to identify the conflict. There are four basic steps in double loop theory learning process. Therefore, the workshop was developed adapting the four steps. 78 students who experienced teaching practice in kindergarten were divided into groups and implemented the workshop in 2019. Their assumptions underlying current views were questioned and hypotheses about behavior tested in the workshop. As a result, it was clarified that the workshop using double loop learning had enhanced the student teachers' reflection beyond their espoused theory and theory-in-use.
\end{abstract}

Keywords: espoused theory; professional development; reflective practitioner; student teaching;

theory-in-use 